\title{
Phytochemical and comparative antidiabetic studies of leaf extracts of Viscum album from different plant hosts
}

\author{
Uwemedimo F. UMOH ${ }^{1}$, B. A. J. EKPO ${ }^{1}$, D. N. BALA ${ }^{1}$, John A. UDOBANG ${ }^{2 *}$, \\ M. COCOBASSEY ${ }^{1}$ and Emmanuel I. ETIM ${ }^{3}$ \\ ${ }^{1}$ Dept. of Pharmacognosy and Natural Medicine. \\ ${ }^{2}$ Dept. of Pharmacology and Toxicology. \\ ${ }^{3}$ Dept. Pharmaceutical and Medicinal Chemistry, Faculty of pharmacy, University of Uyo, Uyo. \\ ${ }^{*}$ Corresponding author, E-mail: johnudobang2009@yahoo.com, +234-8025693590
}

\begin{abstract}
Phytochemical screening and evaluation of antidiabetic activity of leaf extracts of Viscum album from four different plant hosts were carried out using standard procedures. The results of the phytochemical screening revealed that the different leaf extracts vary in their phytochemical constituents depending on the plant host. Moreso, all the leaf extracts of Viscum album demonstrated significant $(\mathrm{p}<0.001)$ lowering of blood glucose level (BGL) in alloxan-induced diabetic rats. The leaf extract of $V$. album from Dennettia tripetala exhibited the highest antidiabetic activity than the other extracts followed by Citrus sinensis and Pisium guajava and their activities were more pronounced than that of standard drug, glibenclamide during acute study. On prolonged treatment, Viscum album leaf extracts from C. sinensis (VAC) and P. guajava (VAP) had comparably higher antidiabetic effects than the other extracts and glibenclamide. These were followed by that from Dacroydes edulis (VAD) while Dennettia tripetala (VADT) had the lowest antidiabetic effect. Although $V$. album possesses antidiabetic property, its antidiabetic efficacy depends on its phytochemical constituents which in turn depends on the plant host.
\end{abstract}

(C) 2011 International Formulae Group. All rights reserved.

Keywords: Mistletoe, Hyperglycemia, Alloxan, Glibenclamide.

\section{INTRODUCTION}

Viscum album L. (Loranthacea) (mistletoe) is an evergreen hemi-parasite which grows on the branches of a variety of trees. It is widely distributed in tropical and subtropical Africa, Asia and Europe (Duke, 1985). It is used traditionally in the treatment of hypertension and epilepsy (Gills, 1992) as well as diabetes in West Indies (Peters, 1957). The tea is valued in Nigeria especially amongst the Ibibio for its efficacy in the treatment of hypertension and diabetes mellitus. It has antiglycation activities (Choudhary et al., 2010). It prevents changes in levels of RBCs, PCV, Hb, serum protein and ESR in high salt-salt fed rats (Ofem et al., 2009). A number of biological effects, such as anticancer, antimicobacterial, antiviral, apoptosis-inducing and immunomodulatory activities have been reported for it (OnayUcar et al., 2006). Mistletoe teas and infusions are recommended ethno-medicinally for the 
prevention and management of stroke in parts of Nigeria, and it is also believed to improve the circulatory system and heart functions in traditional medicine (Deeni and Sadiq, 2002). They have antioxidant activity which allows them to act as reducing agents, metal chelators and free radical quenchers (Oboh and Rocha, 2007). Studies have reported on the phytochemistry (Boci, 1993; Haas et al., 2003; Oguntoye et al., 2008), antidiabetic (Gray and Flatt, 1999; Ohiri et al., 2003; Nwaegurue et al., 2007), anti-inflammatory, cardiovascular and antimicrobial effects (Alison et al., 2000; Undie and Akubue, 1986; Oguntoye et al., 2008), cytotoxic and immunomodulatory antitumoral effects (Harmsma et al., 2006).

Since $V$. album is not host specific coupled with varying reports on its antidiabetic efficacy, the objective of this study was to carry out the phytochemical screening of $V$. album from four different plant hosts and also determine the antidiabetic activities of $V$. album from the four different hosts.

\section{MATERIALS AND METHODS Plant materials}

Fresh leaves of $V$. album Del. (Loranthacea), were collected from different plant hosts such as sweet orange (Citrus sinensis), African pear tree (Dacroydes edulis), Guava (Psidium guajava), and pepper fruit (Dennettia tripetala) in May, 2009 from the villages around Uyo urban. The plant was identified and authenticated by Dr. Margaret Bassey, a taxonomist in the Department of Botany, University of Uyo, Nigeria. The fresh leaves $(2 \mathrm{~kg})$ of each plant were airdried separately on laboratory tables for 2 weeks and reduced to powder. The powder $(100 \mathrm{~g})$ of each plant was macerated in $95 \%$ ethanol $(300 \mathrm{ml})$ for 72 hours. The liquid filtrates obtained were concentrated in vacuo at $40{ }^{\circ} \mathrm{C}$. The extracts were then stored in a refrigerator at $4{ }^{\circ} \mathrm{C}$ until used for the experiments reported in this study.

\section{Phytochemical screening}

Phytochemical screening of the leaf extracts were carried out by employing standard procedures and tests (Trease and Evans, 1989; Sofowora, 1993), to reveal the presence of chemical constituents such as alkaloids, flavonoids, tannins, terpenes, saponins, anthraquinones, reducing sugars and cardiac glycosides among others.

\section{Animals}

The animals (male and female mice and rats) that were used for these experiments were obtained from the University of Uyo animal house. The animals were housed in standard cages and were maintained on a standard pelleted Feed (Guinea Feed) and water ad libitum. Permission and approval for the animal studies were obtained from the College of Health Sciences Animal Ethics Committee, University of Uyo.

\section{Induction of diabetes}

The animals were fasted overnight and diabetes was induced by a single intraperitoneal injection of a freshly prepared solution of alloxan $(150 \mathrm{mg} / \mathrm{kg}$ body weight) in ice cold $0.9 \% \mathrm{NaCl}$ saline solution. The animals were allowed to drink 5\% glucose solution overnight to overcome the druginduced hypoglycemia. Control rats were injected with normal saline alone. After 72 hours, to allow for the development of diabetes, rats with moderate diabetes having glycosuria and hyperglycemia (blood glucose level range above $150 \mathrm{mg} / \mathrm{dl}$ ) were considered as diabetic and used for the drug treatment. The leaf extracts of the plant from the various hosts in acqueous solution were administered to rats orally through a gavage at a concentration of $100 \mathrm{mg} / \mathrm{kg}$ body weight/rat/day for 14 days.

\section{Experimental design}

The animals were divided into five groups of 6 rats each and treated as follows: Group I: Diabetic rats administered orally with leaf extract of $V$. album from Citrus sinensis (VAC) at a dose of $100 \mathrm{mg} / \mathrm{kg} /$ day in acqueous solution for 14 days.

Group II: Diabetic rats given leaf extract of V. album from Dacroydes edulis (VAD) at a 
dose of $100 \mathrm{mg} / \mathrm{kg} /$ day in acqueous solution orally for 14 days.

Group III: Diabetic rats administered orally with leaf extract of $V$. album from Psidium guajava (VAP) at a dose of $100 \mathrm{mg} / \mathrm{kg} /$ day in acqueous solution for 14 days.

Group IV: Diabetic rats administered orally with leaf extract of $V$. album from Dennettia tripetala (VADT) at a dose of $100 \mathrm{mg} / \mathrm{kg} /$ day in acqueous solution for 14 days.

Group V: Diabetic rats given Glibenclamide (10 $\mathrm{mg} / \mathrm{kg} /$ day) for 14 days in aqueous solution orally for 14 days.

Group VI: Diabetic control rats given normal saline $10 \mathrm{ml} / \mathrm{kg}$ for 14 days.

The fasting blood glucose levels (BGL) of all the rats were recorded at regular intervals during the experimental period. For the acute study, the BGL was monitored after 1,3 and 7 hours of administration of a single dose of the extract, and at the end of 1, 7 and 15 days for the prolonged treatments. The BGL was monitored in the blood of the diabetic rats by the tail tipping method. The blood was dropped on the dextrostix reagent pad.The pad was inserted into microprocessor digital blood glucometer and the readings were noted (WHO, 1980).

\section{Statistical analysis}

Data were reported as mean \pm standard error of the mean (SEM) and were analyzed statistically using One way ANOVA followed by Tukey-kramer multiple comparison test and values of $\mathrm{p}<0.001$ and 0.05 were considered significant.

\section{RESULTS}

\section{Phytochemical screening}

The results of the phytochemical screening of the leaf extracts of $V$. album from various plant hosts showed differential compositions in terms of amount and type of secondary metabolites present (Table 1). $V$. album from Dennettia tripetala (VADT) contained alkaloids, tanins, catechols, saponins, terpenes, flavonoids, and cardiac glycosides, while anthraquinones and phlobatanins were absent. Alkaloids, tannins, catechol, saponins, flavonoids, terpenes and cardiac glycosides were present in the leaf extract of $V$. album from $D$. edulis. In the leaf extract of $V$. album from $P$. guajava, tannins, saponins, flavonoids, anthraquinones, cardiac glycosides and terpenes were found while alkaloids and catechol, phlobatanins and cyanogenic glycosides were absent. V. album from $C$. sinensis had tannins, catechol, saponins, flavonoids, anthraquinones, cardiac glycosides, and terpenes in its leaf extract. Alkaloids, phlobatannins and cyanogenic glycosides were absent.

\section{Evaluation of antidiabetic activity}

During acute study of the effects of the leaf extracts of $V$. album from different plant hosts on BGL of the diabetic rats, all the groups treated with $V$. album leaf extracts exhibited significant $\quad(\mathrm{p}<0.05-0.001)$ reductions in BGL compared to the control. Within one hour of extract administration, VAP and VAD extracts demonstrated higher significant $(\mathrm{p}<0.001)$ antidiabetic effects with $8.32 \%$ and $7.65 \%$ respectively. The highest reduction after 5 hrs was recorded with $V$. album leaf extract from pepper fruit (Dennettia tripetala) (24.8\%). V. album leaf extracts from $P$. guajava and $D$. edulis had comparable effects after 5 hrs with BGL reduction percentages of 20.71 and $20.03 \%$ respectively. The standard drug, glibenclamide $(10 \mathrm{mg} / \mathrm{kg})$, caused $18.62 \%$ BGL reduction after $5 \mathrm{hrs}$, while minimal effect was observed with $V$. album leaf extract from Citrus sinnensis (VAC) $(0.40 \%$, 5hrs) (Figure 1).

On prolonged studies, the leaf extracts of $V$. album from various plant hosts elicited significant effects $(\mathrm{p}<0.001)$ comparable to that of the standard after 14 days of treatment. The leaf extracts of VAC and VAP had comparable highest effects than other extracts and were followed by that of VAD. VADT had the lowest antidiabetic effect. The antidiabetic activities of the extracts were greater than that of the standard drug, glibenclamide (Figure 1). 
Table 1: Results of phytochemical screening of leaf extracts of V. album from different host.

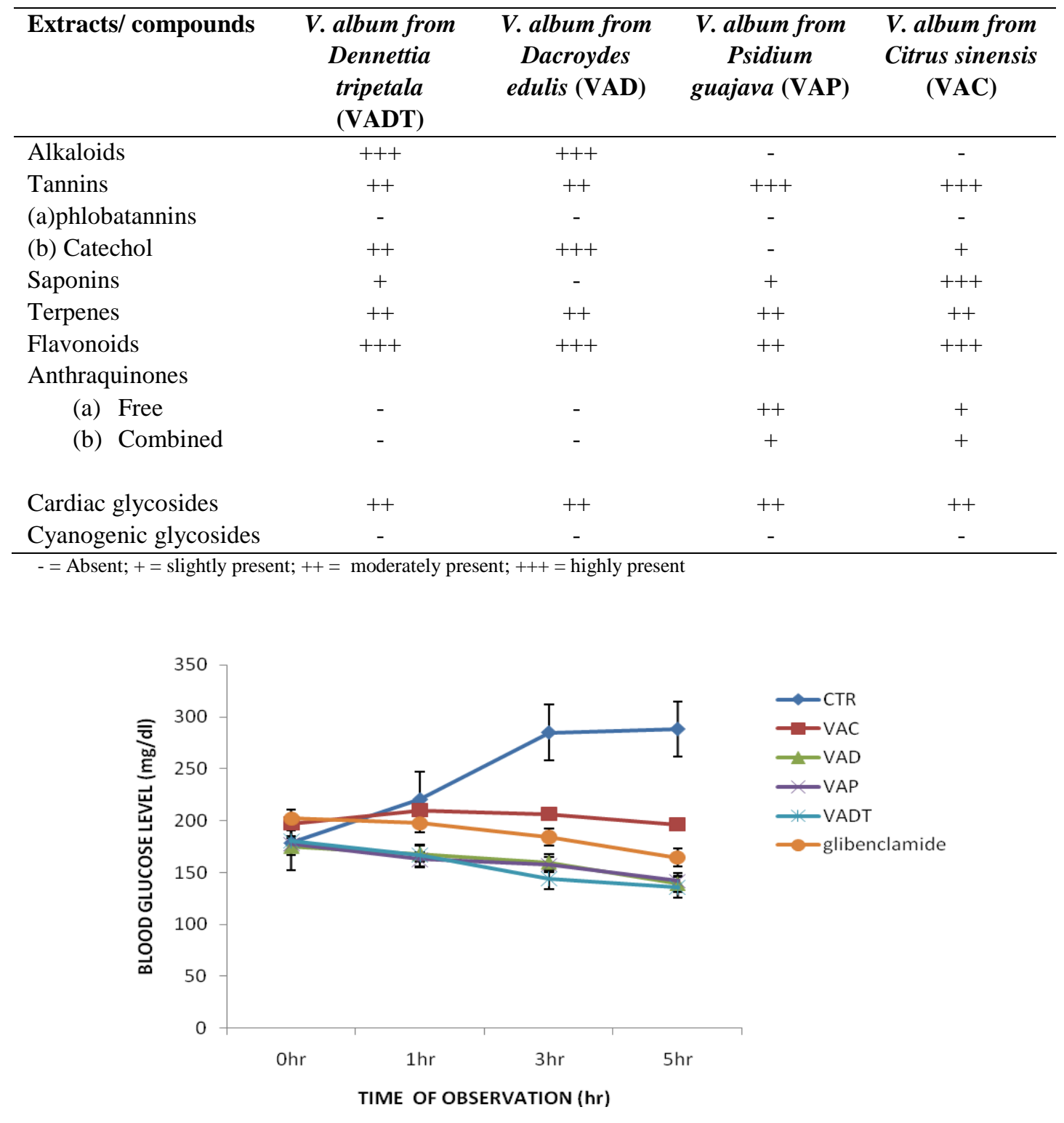

Figure 1: Antidiabetic activities of $V$. album from different host-plants on blood glucose level of alloxan-induced diabetic rats.

\section{DISCUSSION}

In this study, phytochemical and comparative antidiabetic studies were carried out on leaf extracts of $V$. album from different plant hosts. The phytochemical profile of the different leaf extracts of $V$. album revealed constituents ranging from alkaloids, saponins, tannins, flavonoids, anthraquinones, catechols, cardiac glycosides, terpenes to cyanogenic glycosides which is host related and this in turn affected the medicinal potentials of these extracts. The antidiabetic effects of the different leaf extracts of $V$. album have been evaluated in this study. The results showed 
that, though all the leaf extracts caused significant reductions in BGL of the alloxaninduced diabetic rats, VAP and VADT extracts had highest significant antihyperglycemic activities which was more than that of other extracts and glibenclamide (in acute study). During prolonged study, VAC and VAP with comparable effects had the most pronounced effects more than that of other extracts and glibenclamide. Within the treatment period (14 days), the various combined extracts effects demonstrated significant antidiabetic activities thereby reducing the $\mathrm{BGL}$ of the alloxan-induced diabetic rats to normal. The results of this study corroborate those of Gray and Flatt, (1999), Ohiri et al. (2003) and Nwaegerue et al. (2007), who had earlier reported on the antidiabetic activity of this plant. The differences in their antidiabetic activities could have been due to host-related factors which are reflected on their phytochemical profiles. This shows that the plants have different phytochemistry depending on the host so also their activities. Secondary metabolites have been reported to be involved in antidiabetic activity of many plants (Kako et al., 1997). Different mechanisms of action of antidiabetic plants have been proposed such as potentiation of insulin effect either by increasing the pancreatic secretion of insulin from the cells of islets of Langerhans or its release from bound insulin (Pari and Amarnath, 2004), inhibition of hepatic glucose production (Eddouks et al., 2003), inhibition of intestinal glucose absorption (Youn et al., 2004) or correction of insulin resistance (Hu et al., 2003).The extracts from the four plant hosts contained flavonoids which are known for their antioxidant properties. V. album leaf is known to protect cells through attenuation of lipid peroxidation and decrease of the production of free radical derivatives therefore offering protection against oxidative stress by scavenging of free radicals (Nwanjo, 2007). Study also showed that it maintained the level of non-enzymic antioxidants towards the normal, possibly by improving the GSH status. GSH is a major endogenous antioxidant which counterbalances free radical mediated damage and is involved in the protection of normal cells structure and function by maintaining the redox homeostasis, quenching of free radicals and by participating in detoxification reactions (Nwanjo, 2007). It is well established that GSH in blood keeps up the cellular levels of the active forms of vitamins $\mathrm{C}$ and $\mathrm{E}$ by neutralizing the free radicals. When there is a reduction in the GSH, the cellular levels of vitamin $\mathrm{C}$ is also lowered, indicating that GSH, vitamin $\mathrm{C}$, and vitamin $\mathrm{E}$ are closely interlinked to each other (Pari and Amadi, 2005).

Although Gray and Flatt (1999) had reported that $V$. album leaf extract stimulates insulin secretion from islet cells, these leaf extracts may have exerted their antidiabetic effects by utilizing one or more of the above mechanisms. A combination of these mechanisms could have resulted in the significant antidiabetic activity observed in this study.

The findings of this study confirms that the antidiabetic efficacy of the leaf extracts of $V$. album used traditionally by herbalists of Ibibio tribe of Akwa Ibom State, Nigeria for the management of diabetes differs, depending on the plant hosts. Further investigation is being advocated into the factors responsible for the host related differences affecting the use of this plant in the management of diabetes .

\section{ACKNOWLEDGMENT}

The authors are grateful to Mr. Nsikan Malachy of Pharmacology and Toxicology Dept, University of Uyo, Uyo, Nigeria for his technical assistance.

\section{REFERENCES}

Alison M, Yasser HA, Abdel W, Flatt PR. 2000. The traditional plant treatments of Sameucus nigra (Elder) exhibits insulinlike and insulin-releasing activities in vitro. J. Nutr., 130: 15-20.

Bocci B. 1993. Mistletoe (Viscum album) lectins as cytokine inducers and immuno- 
adjuvants in tumour therapy. A review. Journal of Biology and Rugulatory Homoeostatic Agents, 7: 1- 6.

Bown D. 1995. The Royal Horticultural Society Encyclopedia of Herbs and Their Uses. Dorling Kindersley Ltd: London.

Choudhary MI, Maher S, Begum A, Abbaskhan A, Ali S, Khan A, Shafiqueur-Rehman Atta-ur-Rahman. 2010. Characterization and antiglycation activity of phenolic constituents from Viscum album (European Mistletoe). Chem. \& Pharm. Bull., 58(7): 980-982.

Deeni YY, Sadiq NM. 2002. Antimicrobial properties and phytochemical constituents of leaves of African mistletoe (Tapinanthus dodoneifolius (DC) Danser) (Loranthaceae): an ethnomedicinal plant of Hausaland, Northern Nigeria. $J$. Ethnopharmacol., 83(3): 235-240.

Duke, JA. 1985. Mistletoe. In Handbook of Medicinal Herbs. CRC Press: Florida; $512-513$.

Edduoks M, Jouad H, Maghrani M, Lemhadri A, Burcelin R. 2003. Inhibition of endogenous glucose production accounts for hypoglycemic effect of Spergularia purpurea in streptozotocin induced diabetic mice. Phytomedicine, 10: 594 599.

Gills LS. 1992. Viscum album L. Ethnomedical uses of Plants in Nigeria. University of Benin Press: Benin; 244245.

Gray AM, Flatt PR. 1999. Insulin- secreting activity of the traditional antidiabetic plant Viscum album (mistletoe). Journal of Endocrinology, 160: 409 - 414.

Haas K, Bauer M, Wollenweber E. 2003. Cuticular waxes and flavonol aglycones of mistletoe. Zurich Naturforsch, 58c: $464-470$.

Harmsma M, Ummelen M, Dignef W, Tusenius KJ, Ramaekers FC. 2006. Effects of mistletoe (Viscum album L.) extract Iscador on cell cycle and survival of tumor cells. Arzneimittelforschung, 56(6A): 474-82.
Hu X, Sato J, Oshida Y, Xu M, Bajotto G, Sato Y. 2003. Effect of Goshajinki-Gan (Chinese herbal medicine: Niu-che-senQi-wan) on insulin resistance in streptozotocin induced diabetic rats. Diabetes Res. Clin. Pract., 59: 103 111.

Kako M, Miura T, Nishiyama Y, Ichimaru M, Moriyasu M, Kato A. 1997. Hypoglycaemic activity of some triterpenoid glycosides. J Nat Prod., 60: $604-605$.

Nwanjo HU. 2007. Free radicals scavenging potential of the aqueous extract of Viscum album (Mistletoe) leaves in diabetic Wistar rats hepatocytes. The Internet Journal of Nutrition and Wellness, 3: 2.

Nwaegerue E, Nweke IN, Ezeala CC, Unekwe PC. 2007. Glucose lowering effect of leaf extracts of Viscum album in normal and diabetic rats. J. Res. Med. Sc., 12(5): 235240.

Oboh G, Rocha JBT. 2007. Polyphenols in red pepper (Capsicum annuum var. aviculare (Tepin)] and their protective effect on some pro-oxidants induced lipid peroxidation in brain and liver in vitro. Eur. Food Res. Technol., 225(2): 239 249.

Ofem OE, Eno AE, Nku CO, Antai AB. 2009. Viscum album (mistletoe) extract prevents changes in levels of red blood cells, PCV, $\mathrm{Hb}$, serum proteins and ESR in high saltfed rats. J. Ethnopharmacol., 126(3): 421-426.

Onay-Ucar E, Karagoz A, Arda N. 2006. Antioxidant activity of Viscum album ssp. album. Fitoterapia, 77: 556-560.

Ogutoye SO, Olatunji GA, Kolawole OM, Enonbun KI. 2008. Phytochemical screening and antibacterial activity of Viscum album (mistletoe) extracts. Plant Sciences Research, 1(3): 44 - 46.

Ohiri FC, Esimonu CO, Nwafor SV, Okoli $\mathrm{CO}, \mathrm{Ndu}$ OO. 2003. Hypoglycaemic properties of Viscum album in alloxan induced diabetic animals. Pharmaceutical Biology, 4: 184- 192. 
Pari L, Amadi R. 2005. Protective role of tetrahydrocurcumin (THC) an active principle of tumeric on chloroquine induced hepatotoxicity in rats. J. Pharm. Pharmaceut. Sci., 8(1): 115-123.

Peters G. 1957. Review of insulin substitutes from vegatable sources. Deutsche Medicizin Wochenschrift., 82: 320 - 322.

Sofowora A. 1993. Medicinal Plants and Traditional Medicine in Africa ( $2^{\text {nd }}$ edn). Spectrum Books Limited: Ibadan, Nigeria; 97 - 145.

Tiwari AK, Rao JM. 2002. Diabetes mellitus and multiple approaches of phytochemicals: present status and future prospects. Curr Sci., 83(1): $30-37$.
Trease GE, Evans WC. 1989. Pharmacognosy $\left(13^{\text {th }}\right.$ edn). Bailliere Tindall: London; 683-684.

Undie AS, Akubue PI. 1986. Pharmacological evaluation of Discorea dumentorum tuber used in traditional antidiabetic therapy. $J$. Ethnopharmacol., 15: 133 - 144.

WHO expert committee on diabetes mellitus. Tech. Rep. Series No.646. World Health Organisation: Geneva, 1980.

Youn J, Park HY, Cho KH. 2004. Antihyperglycemic activity of Commelina communis L.: Inhibition of alpha-glucosidase. Diabetes Res. Clin. Pract., 66: S149-S155. 